\title{
Maternal and neonatal characteristics in obstetric intensive care unit admissions
}

\section{Seppänen, P.M.}

2020-02

Seppänen , P M , Sund , R T , Uotila , J T , Helminen , M T \& Suominen , T M 2020 , '

Maternal and neonatal characteristics in obstetric intensive care unit admissions ' , International Journal of Obstetric Anesthesia , vol. 41 , pp. 65-70 . https://doi.org/10.1016/j.ijoa.2019.07.002

http://hdl.handle.net/10138/317355

https://doi.org/10.1016/j.joa.2019.07.002

acceptedVersion

Downloaded from Helda, University of Helsinki institutional repository.

This is an electronic reprint of the original article.

This reprint may differ from the original in pagination and typographic detail.

Please cite the original version. 


\section{Accepted Manuscript}

Original Article

Maternal and neonatal characteristics in obstetric intensive care unit admissions

P.M. Seppänen, R.T. Sund, J.T. Uotila, M.T. Helminen, T.M. Suominen

PII:

S0959-289X(19)30142-6

DOI:

https://doi.org/10.1016/j.ijoa.2019.07.002

Reference:

YIJOA 2824

To appear in:

International Journal of Obstetric Anesthesia

Accepted Date: $\quad 2$ July 2019

Please cite this article as: Seppänen, P.M., Sund, R.T., Uotila, J.T., Helminen, M.T., Suominen, T.M., Maternal and neonatal characteristics in obstetric intensive care unit admissions, International Journal of Obstetric Anesthesia (2019), doi: https://doi.org/10.1016/j.ijoa.2019.07.002

This is a PDF file of an unedited manuscript that has been accepted for publication. As a service to our customers we are providing this early version of the manuscript. The manuscript will undergo copyediting, typesetting, and review of the resulting proof before it is published in its final form. Please note that during the production process errors may be discovered which could affect the content, and all legal disclaimers that apply to the journal pertain. 
Maternal and neonatal characteristics in obstetric intensive care unit admissions

PM Seppänen, ${ }^{\mathrm{a}}$ RT Sund, ${ }^{\mathrm{b}}$ T Uotila, ${ }^{\mathrm{c}}$ MT Helminen, ${ }^{\mathrm{d}}$ TM Suominen ${ }^{\mathrm{a}}$

aTampere University, Faculty of Social Sciences, Finland

${ }^{b}$ Institute of Clinical Medicine, University of Eastern Finland, Kuopio Finland AND Centre for

Research Methods, Faculty of Social Sciences, University of Helsinki, Finland

${ }^{c}$ Tampere University and Tampere University Hospital, Finland

${ }^{d}$ Tampere University Hospital and Faculty of Social Sciences, Tampere University, Finland

Corresponding author: PM Seppänen

E-mail address: pia.seppanen@pshp.fi

\section{CONFLICT OF INTEREST}

The authors declare that they have no potential conflict of interest.

\section{ABSTRACT}

Background: The objective of this study was to evaluate the course of pregnancy and delivery of obstetric patients admitted for intensive care, and determine the health status of their infants.

Methods: This was a retrospective register-based study. Four university hospitals in Finland participated. Obstetric patients admitted to the intensive care unit in any trimester of pregnancy, during delivery or up to 42 days post partum were identified from clinical information systems over a five-year study period. Parturient and infant data were collected from the Medical Birth Register.

Results: During the study period (2007-2011), 283 obstetric patients were identified from the clinical information system. The most common reason for admission was hypertensive complications (58\%), followed by obstetric haemorrhage (25.1\%). Advanced maternal age, nulliparity and multiple pregnancies were associated with obstetric intensive care unit admissions. Of patients admitted to intensive care, $68.9 \%$ delivered by unscheduled caesarean section. Nearly $60 \%$ of neonates were born preterm, $56.1 \%$ needed treatment in a neonatal intensive care unit or an observation unit and $4.6 \%$ died within one week. 
Conclusion: Advanced maternal age, nulliparity and multiple pregnancy were more common among intensive care unit-admitted women than in the general obstetric population. The main causes for admission were hypertensive complications and obstetric haemorrhage. Compared with the general obstetric population, neonates of intensive care unit-admitted mothers were eight times more likely to require treatment on a neonatal ward and their risk of neonatal death was also eight times greater.

Keywords: Delivery; Labour; Obstetrics; Pregnancy complications; Risk factors 


\section{Introduction}

Severe acute maternal morbidity, also called a 'near miss', is defined by the World Health Organization as 'a woman who nearly died, but survived a complication that occurred during pregnancy, childbirth or within 42 days of termination of pregnancy'. ${ }^{1}$ The most common maternal morbidities leading to intensive care are cardiovascular instability related to haemorrhage and severe pre-eclampsia. ${ }^{2-4}$ Some complications exist before pregnancy but are worsened during pregnancy or childbirth and lead to intensive care unit (ICU) admission. The most common reasons for non-obstetric ICU admission are heart disease and infections, ${ }^{5-7}$ The incidence of obstetric critical care admission in resource-rich countries varies between 0.4 and1.6\%.8-12

Recent studies have focused on the condition and treatment of obstetric patients during their ICU stay, and some have reported the characteristics and outcomes of pregnant and post-partum women. ${ }^{13}$ Preterm delivery and perinatal death have been reported to be more common among ICUadmitted mothers. ${ }^{14-16}$

Finland has a comprehensive system of national registers of specific clinical conditions as a method to allow epidemiological studies, and a considerable amount of data are available in clinical information systems. A register-based study is an appropriate method to investigate infrequent phenomena such as complications resulting in intensive care during pregnancy or post partum. The objectives of our study were: 1) to evaluate the course of pregnancy and delivery in obstetric patients admitted to ICU; 2) to determine the health status of infants born to those women; 3 ) to compare the results with reference data on Finnish parturients and infants.

\section{Methods}

This was a retrospective register-based study involving four university hospitals in Finland between January 2007 and December 2011. All women admitted to ICU in any trimester of pregnancy and up to 42 days post partum were identified from the hospital databases. The Ethics Committee of the Pirkanmaa hospital district approved the study protocol (decision number R12050H).

Patients were identified using the Acute Physiology and Chronic Health Evaluation (APACHE) III, which is mandatorily recorded data on all ICU-admitted patients. ${ }^{17}$ The APACHE III database was searched for the classification 'other gynaecological disease', which includes diagnoses related to pregnancy, delivery and the post-partum period. All women aged 18-50 years were identified. 
Detailed causes of ICU admission were collected from each hospital's database. Causes of obstetric intensive care unit admissions were re-categorised as follows; eclampsia, severe pre-eclampsia, other hypertensive conditions (hypertension without proteinuria, mild pre-eclampsia, undefined preeclampsia), obstetric haemorrhage, miscellaneous obstetric reasons and non-obstetric causes.

Data regarding pregnancy, childbirth and infant health were obtained from the Medical Birth Register (MBR) maintained by the National Institute of Health and Welfare in Finland. The MBR was established in 1987 and includes data on live births and on stillbirths of fetuses with a birthweight of at least $500 \mathrm{~g}$ or a gestational age of at least 22 weeks, and data on the mothers. ${ }^{18}$

The data derived from the MBR included: 1) parturient characteristics; 2) factors related to the current pregnancy; 3) factors related to the delivery; 4) infant characteristics. The reference data on Finnish parturients and infants were collected from the MBR. The data comprised all women who delivered during the same time period (2007-2011) and at the same university hospitals as the study population. The reference data included 79340 parturients and 80829 infants.

Descriptive statistics for obstetric patient data and reference data are presented as frequencies, percentages and mean values. Factorial variable comparisons between these groups were made using chi-square tests or Fisher exact tests, where appropriate. Continuous variable comparisons were made using one sample t-test. Statistical analyses were made using R version 3.3.0 (R Core Team (2016). R: A language and environment for statistical computing. R Foundation for Statistical Computing, Vienna, Austria) and IBM SPSS Statistics version 23.0. Because of the large number of data, statistical significance was defined as a $p$ value of less than 0.001 .

\section{Results}

In the period from January 2007, to December 2011, 328 patients were identified from the clinical information systems. Forty-five patients were excluded for the following reasons: gynaecological patients $(n=37)$; missing MBR information $(n=7)$; maternal death in ICU $(n=1)$. Parturient and infant data were available from the MBR for 283 ICU-admitted obstetric patients. The causes of obstetric ICU admission are presented in Table 1.

The characteristics of parturients are shown in Table 2. The patients admitted to ICU were significantly older than the reference birthing population. They were more often nulliparous, and they were more likely to have had multiple pregnancies. Smoking status and body mass index did not show significant differences between the groups. 
Table 3 describes factors related to current pregnancy and delivery. Pregnancy among ICUadmitted mothers had more often originated in fertility treatment, and during pregnancy they had more hypertensive complications than the reference population. Mode of delivery differed greatly between these obstetric patients and the reference population: among those admitted to an ICU, $80 \%$ delivered by caesarean section (CS). Manual removal of the placenta and uterine evacuation, placental abruption, eclampsia and blood transfusion during delivery were more common among ICU-admitted mothers.

Table 4 describes infant characteristics. Gestational age at birth was lower among infants of ICUadmitted patients, nearly $60 \%$ of women were delivered before 37 gestational weeks, and almost 9\% had extremely preterm births ( $<28$ weeks of pregnancy). Consequently, birthweight also differed between the study population and the reference group. Up to $77 \%$ of those admitted for hypertensive complications delivered preterm at $<37$ weeks of pregnancy, and $11 \%$ had an extremely preterm delivery at $<28$ weeks of pregnancy, while obstetric haemorrhage was mostly associated with full-term birth (75\%). Infants born to ICU-admitted mothers frequently needed treatment in a neonatal ICU (NICU) or an observation unit. At the age of seven days, half the infants born to ICU-admitted mothers still needed treatment on neonatal wards and $4.6 \%$ had died (reference value $0.61 \%$ ).

\section{Discussion}

The objective of this study was to evaluate retrospectively the course of pregnancy and delivery in women admitted to ICU, determine the health status of their infants, and compare the results with reference data for Finnish parturients and infants. Our results are in line with previous studies showing that the most frequent reasons for ICU admission are hypertensive diseases of pregnancy. ${ }^{13}$ However, in the UK the most frequent cause of admission to ICU for pregnant and recently pregnant women is haemorrhage rather than hypertensive disease of pregnancy. ${ }^{19}$ It is possible that, in Finland, university hospital administrative practice may vary and that some obstetric patients were treated somewhere other than ICU, for example in a recovery ward after obstetric haemorrhage. Compared with the general obstetric intensive care unit population, the ICU-admitted obstetric population in our study had low birthweight infants more frequently, and their newborns more frequently needed treatment in NICU or an observation unit. The incidence of preterm birth was higher in mothers admitted for hypertensive complications and non-obstetric reasons.

We did not collect data on the number of births in each hospital, but used statistics on live births in different hospital districts in Finland. Based on the freely available information on the Statistics 
Finland website, ${ }^{20}$ during the study period there were 94642 births in four hospital districts where data were collected. A total of 291 obstetric admissions were collected from the clinical information system, which was $0.3 \%$ of all maternities $(0.02-0.5 \%)$.

The ICU-admitted mothers were older than the reference population. The association between advanced maternal age and poorer birth outcomes has been well described. The proportion of operative deliveries increases substantially with maternal age. ${ }^{21-23}$ Advanced maternal age carries a higher risk of birth before 34 weeks of gestation, ${ }^{24}$ severe haemorrhage,${ }^{25}$ emergency peripartum hysterectomy ${ }^{26}$ and blood transfusion at delivery ${ }^{27}$. Our results showing an increased risk of ICU admission among older parturients are probably explained by the increased risk of these complications. In a study by Goisis et al., advanced maternal age increased the risk of low birthweight and preterm birth; nulliparous women at very advanced maternal age ( $\geq 45)$ were at risk of preterm delivery and CS, and the infants of these women were more likely to need treatment in NICU. ${ }^{28}$ The mean age of parturients has increased in recent years. According to Nordic perinatal statistics, the mean age of all parturients has risen in all Nordic countries: the mean age of nulliparous parturients in 2016 was 28.5 years, while four decades earlier the mean age had been 23.5 years. At the same time, the proportion of parturients of advanced maternal age has increased considerably. ${ }^{29}$ The need for ICU treatment caused by pregnancy and delivery complications should not be expected to decrease in the future.

It is notable that only one mother died in ICU during the study period. Over the last decade in Finland, approximately three women have died annually during pregnancy or in the post-partum period. ${ }^{20}$ This is the lowest incidence in the world, and the most common reasons were embolism related to delivery or obstetric hemorrhage.

In our study, $60 \%$ of infants were born below a gestational age of 37 weeks, more than half had a birthweight below $2500 \mathrm{~g}$, the majority of infants needed treatment in NICU or an observation unit, and almost 5\% died during the neonatal period. This demonstrates the challenges presented by obstetric ICU patients for staff: not only must the mother's physical condition be treated, but at same time the condition of the newborn may be critical, and mother-child separation is often unavoidable. Cartin-Ceba et al. investigated non-obstetric critical illness in pregnant women: one third of pregnancies ended in fetal loss during ICU admission, and nearly half of all live births were premature ${ }^{16}$. Madan et al. assessed perinatal outcomes and found that infants born to ICU-admitted mothers were more likely to need NICU admission and intubation. ${ }^{30}$ 
The principal strengths of our study are the description of the Finnish obstetric intensive care and the data on neonatal outcomes, and its nationwide, multicentre nature. The MBR provided detailed and systematically collected register-based information, and reference data were available for comparison. By using the clinical information systems and the MBR, it was possible to constitute a comprehensive population of intensive care unit admitted obstetric patients over a long-term period. The results of this study increase the understanding of the background of these mothers, and determining the course of their pregnancy and delivery, and infant health status.

The study was limited by the infant data, which were available only up to the age of seven days. More detailed information is needed to explore infants' long-term outcomes. The register-based study does not provide more accurate information on intensive care treatment or pregnancy and childbirth.

In conclusion, this study found an association between ICU admissions and advanced maternal age, nulliparity and multiple pregnancies. The causes leading to obstetric intensive care admission were mainly hypertensive complications and obstetric haemorrhage. The patients' situation is often complicated by the fact that the newborn may be seriously ill and often needs treatment in NICU or the family may experience the loss of a child. Care should focus on the whole family and their psychological support, not just the mother in ICU.

\section{References}

1. Pattinson R, Say L, Souza JP, van den Broek N, Rooney C, on behalf of the WHO Working Group on Maternal Mortality and Morbidity Classification. WHO maternal deaths and nearmiss classification. Bulletin of the World Health Organization 2009;87:734.

2. Zanconato G, Cavaliere E, Vassanelli A, Schweiger V, Cipriani S, Franchi M. Severe maternal morbidity in a tertiary care centre of northern Italy: a 5-year review. J Matern Fetal Neonatal Med 2012;25:1025-8.

3. Almerie Y, Almerie MQ, Matar HE, Shahrour Y, Chamat AAA, Abdulsalam A. Obstetric near-miss and maternal mortality in maternity university hospital, Damascus, Syria: a retrospective study. BMC Pregnancy Childbirth 2010 Oct 19;10:65. 
4. Murphy CM, Murad K, Deane R, Byrne B, Geary MP, McAuliffe FM. Severe maternal morbidity for 2004-2005 in the three Dublin maternity hospitals. Eur J Obstet Gynecol Reprod Biol 2009;143:34-7.

5. Chantry AA, Deneux-Tharaux C, Bonnet MP, Bonnet MP, Bouvier-Colle MH. Pregnancyrelated ICU admissions in France: Trends in rate and severity, 2006-2009. Crit Care Med 2015;43:78-86.

6. Wanderer JP, Leffert LR, Mhyre JM, Kuklina EV, Callaghan WM, Bateman BT. Epidemiology of obstetric-related ICU admissions in Maryland: 1999-2008. Crit Care Med 2013;41:1844-52.

7. Zwart JJ, Dupuis JRO, Richters A, Öry F, van Roosmalen J. Obstetric intensive care unit admission: a 2-year nationwide population-based cohort study. Intensive Care Med 2010;36: 256-63.

8. Yuqi L, Tan G, Chengming S, Xuri S. The ICU is becoming a main battlefield for severe maternal rescue in China: an 8-year single-center clinical experience. Crit Care Med 2017;45.e1106-45.e1110

9. Vasquez DN, Das Neves AV, Vidal L et al. Characteristics, outcomes, and predictability of critically ill obstetric patients: a multicenter prospective cohort study. Crit Care Med 2015; 43:1887-97.

10. Bandeira ARAP, Rezende CAL, Reis ZSN, Barbosa AR, Peret FJA, Cabal ACV. Epidemiologic profile, survival, and maternal prognosis factors among women at an obstetric intensive care unit. Int J Gynaecol Obstet 2014;124:63-6.

11. Paxton JL, Presneill J, Aitken L. Characteristics of obstetric patients referred to intensive care in an Australian tertiary hospital. Aust NZ J Obstet Gynaecol 2014;54:445-9. 
12. Crozier TM, Wallace EM. Obstetric admissions to an integrated general intensive care unit in a quaternary maternal facility. Aust NZ J Obstet Gynaecol 2011;51:233-8.

13. Pollock W, Rose L, Dennis CL. Pregnant and postpartum admissions to the intensive care unit: a systematic review. Intensive Care Med 2010;36:1465-74.

14. Hezelgrove JF, Price C, Pappachan VJ, Smith GB. Multicenter study of obstetric admissions to 14 intensive care units in southern England. Crit Care Med 2001;29:770-4.

15. Loverro G, Pansini V, Greco P, Vimercati A, Parisi AM, Selvaggi L. Indications and outcome for intensive care unit admission during puerperium. Arch Gynecol Obstet 2001;265:195-8.

16. Cartin-Ceba R, Gajic O, Iyer VN, Vlahakis NE. Fetal outcomes of critically ill pregnant women admitted to the intensive care unit for nonobstetric causes. Crit Care Med 2008;36:2746-51

17. Knaus WA, Wagner DP, Draper EA, Bergner M, Murphy D, Harrell FE. The APACHE III prognostic system: risks prediction of hospital mortality for critically ill hospitalized adults. Chest 1991;100:161936.

18. The National Institute for Health and Welfare. 2018. Medical Birth Register. Available at: https://www.thl.fi/fi/web/thlfi-en/statistics/information-on-statistics/registerdescriptions/newborns. Accessed August 6, 2018.

19. The Obstetric Anaesthetists' Association. 2013. Female admissions (aged 16-50 years) to adult, general critical care units in England, Wales and Northern Ireland reported as 'currently pregnant' or 'recently pregnant'. Report from the Intensive Care National Audit and Research Centre 1 January 2009 to 31 December 2012. 
20. Statistics of Finland. Available at: http://pxnet2.stat.fi/PXWeb/pxweb/fi/StatFin/StatFin. Accessed August 6, 2018.

21. Burke N, Burke G, Breathnach F, et al. Prediction of caesarean section in the term nulliparous woman: results from the prospective, multicentre Genesis study. Am JObstet Gynecol 2017;216:598.e1-598.e11

22. Mesterton J, Lindgren P, Abreu AK, et al. Case mix adjustment of health outcomes, resource use and process indicators in childbirth care: a register-based study. BMC Pregnancy Childbirth 2016;16:125.

23. Omih EE, Lindow S. Impact of maternal age on delivery outcomes following spontaneous labour at term. J Perinat Med 2016;44:773-7.

24. Fredriksen LE, Ernst A, Brix N, et al.. Risk of adverse pregnancy outcomes at advanced maternal age. Obstet Gynecol 2018;3:457-63.

25. Pallasmaa N, Ekblad U, Gissler M, Alanen A. The impact of maternal obesity, age, preeclampsia and insulin dependent diabetes on severe maternal morbidity by mode of delivery - a register-based cohort study. Arch Gynecol Obstet 2015;291:311-8.

26. Macharey G, Ulander VM, Kostev K, Väisänen-Tommiska M, Ziller V. Emergency peripartum hysterectomy and risk factors by mode of delivery and obstetric history: a 10year review from Helsinki University Central hospital. J Perinat Med 2015;43:721-8.

27. Jakobson M, Gissler M, Tapper AM. Risk factors for blood transfusion at delivery in Finland. Acta Obstet Gynecol Scand 2013;92:414-42. 
28. Goisis A, Remes H, Barclay K, Martikainen P, Myrskylä M. Advanced maternal age and the risk of low birth weight and preterm delivery: a within-family analysis using Finnish population registers. Am J Epidemiol 2017;186:1219-26.

29. The National Institute of Health and Welfare. Nordic perinatal statistics 2016. Available at: http://urn.fi/URN:NBN:fi-fe201803053741. Accessed August 6, 2018.

30. Madan I, Puri I, Jain NJ, Grotegut C, Nelson D, Dandolu V. Characteristics of obstetric intensive care unit admissions in New Jersey. J Matern Fetal Neonatal Med 2009;22:78590. 
Table 1. Causes of obstetric intensive care unit admission $(n=283)$

\begin{tabular}{lll}
\hline Causes & $\mathrm{n}$ & $\%$ \\
\hline Obstetric causes & 13 & 4.6 \\
Eclampsia & 99 & 35.0 \\
Severe pre-eclampsia & 52 & 18.4 \\
Other hypertensive conditions & 71 & 25.1 \\
Obstetric haemorrhage & 27 & 9.5 \\
Miscellaneous obstetric reasons & 21 & 7.4 \\
Non-obstetric causes & & \\
\hline
\end{tabular}


Table 2. Parturient characteristics

\begin{tabular}{|c|c|c|c|c|}
\hline \multirow[t]{2}{*}{ Characteristics } & \multicolumn{2}{|c|}{ Obstetric ICU patients } & \multicolumn{2}{|c|}{ Reference values } \\
\hline & $\mathrm{n}$ & $\%$ & $\mathrm{n}$ & $\%$ \\
\hline \multicolumn{5}{|l|}{ Age } \\
\hline$<20 \mathrm{y}$ & 5 & 1.8 & 1802 & 2.3 \\
\hline $20-34 y$ & 201 & 71.0 & 64028 & 80.7 \\
\hline$\geq 35 y$ & 77 & 27.2 & 13510 & 17.0 \\
\hline \multicolumn{5}{|l|}{ Previous deliveries } \\
\hline 0 & 179 & 63.3 & 33091 & 41.7 \\
\hline $1-2$ & 184 & 29.7 & 37691 & 47.5 \\
\hline$\geq 3$ & 20 & 7.1 & 8558 & 10.8 \\
\hline Multiple pregnancy & 22 & 7.8 & 2942 & 3.6 \\
\hline \multicolumn{5}{|l|}{ Smoking status } \\
\hline Non-smoking & 236 & 83.4 & 65491 & 82.5 \\
\hline $\begin{array}{l}\text { Quit in early stages of } \\
\text { pregnancy }\end{array}$ & 7 & 2.5 & 3932 & 5.0 \\
\hline $\begin{array}{l}\text { Smoking at any stage of } \\
\text { pregnancy }\end{array}$ & 16 & 5 & 7253 & 9.1 \\
\hline Missing & 24 & 8.4 & 2664 & 3.4 \\
\hline \multicolumn{5}{|l|}{ Body mass index $\left(\mathrm{kg} / \mathrm{m}^{2}\right)$} \\
\hline$<20$ & 38 & 14.0 & 12424 & 15.7 \\
\hline $20-24.9$ & 130 & 47.8 & 40762 & 51.4 \\
\hline $25-29.9$ & 66 & 24.3 & 16828 & 21.2 \\
\hline $30-34.9$ & 22 & 8.1 & 6228 & 7.9 \\
\hline$\geq 35$ & 16 & 5.8 & 3098 & 3.9 \\
\hline
\end{tabular}


ICU: intensive care unit. 
Table 3. Factors related to current pregnancy and delivery

\begin{tabular}{|c|c|c|c|c|c|}
\hline \multirow[t]{2}{*}{ Variable } & \multicolumn{2}{|c|}{$\begin{array}{l}\text { Obstetric ICU } \\
\text { patients }\end{array}$} & \multicolumn{2}{|c|}{$\begin{array}{l}\text { Reference } \\
\text { population }\end{array}$} & \multirow[t]{2}{*}{$\begin{array}{c}P- \\
\text { value }\end{array}$} \\
\hline & $\mathrm{n}$ & $\%$ & $\mathrm{n}$ & $\%$ & \\
\hline \multicolumn{6}{|l|}{ Diseases during pregnancy } \\
\hline Gestational diabetes ${ }^{1}$ & 24 & 9.8 & 10012 & 12.5 & 0.11 \\
\hline $\begin{array}{l}\text { Gestational hypertension without } \\
\text { significant proteinuria }{ }^{2}\end{array}$ & 42 & 18.3 & 3298 & 4.2 & \\
\hline $\begin{array}{l}\text { Gestational hypertension with } \\
\text { proteinuria }^{3}\end{array}$ & 98 & 42.6 & 1858 & 2.3 & $\begin{array}{l}< \\
0.001\end{array}$ \\
\hline Anaemia & 15 & 5.3 & 2277 & 2.9 & 0.024 \\
\hline \multicolumn{6}{|l|}{ Other pregnancy-related factors } \\
\hline Previous CS & 40 & 14.1 & 7835 & 9.9 & 0.022 \\
\hline Assisted fertility treatment & 13 & 4.6 & 1480 & 1.9 & 0.002 \\
\hline Antenatal corticosteroids & 99 & 35.0 & 3113 & 3.9 & $\begin{array}{l}< \\
0.001\end{array}$ \\
\hline \multicolumn{6}{|l|}{ Mode of delivery } \\
\hline Vaginal & 54 & 19.1 & 68099 & 84.3 & $\begin{array}{l}< \\
0.001\end{array}$ \\
\hline Elective CS & & 12.0 & 5435 & 6.7 & \\
\hline Urgent CS & 168 & 59.4 & 6232 & 7.7 & \\
\hline Emergency CS & 27 & 9.5 & 1063 & 1.3 & \\
\hline \multicolumn{6}{|l|}{ Procedures related to delivery } \\
\hline Epidural analgesia & 67 & 23.7 & 35159 & 45.6 & $\begin{array}{l}< \\
0.001\end{array}$ \\
\hline Induced labour & 45 & 15.9 & 13591 & 17.1 & 0.632 \\
\hline Manual removal of placenta & 10 & 3.5 & 742 & 0.9 & $\begin{array}{l}< \\
0.001\end{array}$ \\
\hline Uterus evacuation & 18 & 6.4 & 583 & 0.7 & $\begin{array}{l}< \\
0.001\end{array}$ \\
\hline Blood transfusion during delivery & 38 & 13.4 & 985 & 1.2 & $\begin{array}{l}< \\
0.001\end{array}$ \\
\hline \multicolumn{6}{|l|}{ Diagnosis related to delivery } \\
\hline Placenta praevia & 2 & 0.7 & 228 & 0.3 & 0.197 \\
\hline Placental abruption & 8 & 2.8 & 193 & 0.2 & $\begin{array}{l}<0 \\
.001\end{array}$ \\
\hline Eclampsia & 16 & 5.7 & 43 & 0.05 & $\begin{array}{l}<0 \\
.001\end{array}$ \\
\hline Fetal asphyxia & 11 & 3.9 & 2369 & 3.0 & 0.475 \\
\hline
\end{tabular}

${ }^{1}$ ICD-10 code O24.4. ${ }^{2}$ ICD-10 code O13. ${ }^{3}$ ICD-10 code O14.

ICU: intensive care unit. CS: caesarean section. 
Table 4. Infant characteristics

\begin{tabular}{|c|c|c|c|c|}
\hline \multirow[t]{2}{*}{ Characteristics } & \multicolumn{2}{|c|}{ Obstetric ICU patients } & \multicolumn{2}{|c|}{ Reference values } \\
\hline & $\mathrm{n}$ & $\%$ & $\mathrm{n}$ & $\%$ \\
\hline \multicolumn{5}{|l|}{ Sex } \\
\hline Female & 162 & 53.1 & 39545 & 48.9 \\
\hline Male & 143 & 46.9 & 41281 & 51.1 \\
\hline \multicolumn{5}{|l|}{ Gestational age (weeks) } \\
\hline$>37$ & 123 & 40.5 & 74148 & 93.5 \\
\hline $34^{+0}-36^{+6}$ & 71 & 23.4 & 3239 & 4.1 \\
\hline $28^{+0}-33^{+6}$ & 83 & 27.3 & 1392 & 1.8 \\
\hline$<28$ & 27 & 8.9 & 561 & 0.7 \\
\hline \multicolumn{5}{|l|}{ Birthweight (g) (median) } \\
\hline & & 2385 & & 3463 \\
\hline$\geq 4500 \mathrm{~g}$ & 3 & 1.0 & 2036 & 2.5 \\
\hline $4000-4499 \mathrm{~g}$ & 20 & 6.6 & 11543 & 14.3 \\
\hline $2500-3999 \mathrm{~g}$ & 114 & 37.4 & 62641 & 77.5 \\
\hline $1500-2499 \mathrm{~g}$ & 90 & 29.5 & 3328 & 4.1 \\
\hline $1000-1499 \mathrm{~g}$ & 45 & 14.8 & 682 & 0.8 \\
\hline$<1000 \mathrm{~g}$ & 33 & 10.8 & 599 & 0.7 \\
\hline \multicolumn{5}{|l|}{ Treatment of newborn } \\
\hline NICU or observation unit & 171 & 56.1 & 9168 & 11.3 \\
\hline Respiratory support & 58 & 19.0 & 1536 & 1.9 \\
\hline \multicolumn{5}{|c|}{ Location of child at age seven days } \\
\hline Home & 114 & 37.5 & 73698 & 91.4 \\
\hline Postnatal ward & & 8.2 & 1391 & 1.7 \\
\hline Neonate ward & 137 & 45.1 & 4662 & 5.8 \\
\hline Other hospital & 14 & 4.6 & 367 & 0.5 \\
\hline Died & 14 & 4.6 & 493 & 0.6 \\
\hline
\end{tabular}

ICU: intensive care unit. NICU: neonatal intensive care unit. 


\section{HIGHLIGHTS}

- Contributing factors for obstetric intensive care unit admission in Finland

- Advanced maternal age, nulliparity and multiple pregnancy are factors

- The most common reason was a hypertensive complication of pregnancy

- The infants born to these mothers have worse short-term outcomes 